\title{
Association of Personal Protective Equipment with De Novo Headaches in Frontline Healthcare Workers during COVID-19 Pandemic: A Cross-Sectional Study
}

\author{
Rumeesha Zaheer ${ }^{1} \quad$ Maheen Khan ${ }^{2}$ Ahmed Tanvee \\ ${ }^{1}$ Orthodontics Department, Armed Forces Institute of Dentistry, \\ Combined Military Hospital, Rawalpindi, Pakistan \\ 2Prosthodontics Department, Khyber College of Dentistry, \\ Peshawar, Pakistan \\ ${ }^{3}$ National University of Medical Sciences, Rawalpindi, Pakistan \\ ${ }^{4}$ Department of Prosthodontics and Dental Implantology, College \\ of Dentistry, King Faisal University, Al Ahsa, Saudi Arabia
}

Amal Farooq ${ }^{3}$ Zohaib Khurshid

\begin{abstract}
Address for correspondence Rumeesha Zaheer, BDS, Orthodontics Department, Armed Forces Institute of Dentistry, Combined Military Hospital, Rawalpindi, Pakistan (e-mail: rumeesha786@hotmail.com).
\end{abstract}

Eur J Dent:2020;14(suppl S1):S79-S85
Objectives This study aimed to determine the association of personal protective equipment (PPE) usage with new-onset headaches and exacerbation of pre-existing headache disorders among healthcare workers at the frontlines during coronavirus disease 2019 (COVID-19) pandemic.

Materials and Methods A descriptive cross-sectional survey was conducted across Pakistan in June-July 2020. The study was approved by Ethical Committee, Armed Forces Institute of Dentistry, Rawalpindi (IRB form no.905/Trg-ABP 1K2). A qualitative questionnaire was developed and was shared via different social networks. The questionnaire was closed when 241 responses were received.

Statistical Analysis Descriptive analysis was performed on demographic data. Chi-squared analysis was performed between demographic data and PPE-usage patterns among participants with or without de novo headaches. Univariable and multivariable logistic regression models were used to compare variables with the development of new-onset headaches. Chi-squared test was also performed between demographic data and other factors that may be causing new-onset headaches. A $p$-value $<0.05$ was considered significant.

Results A total of 241 healthcare workers participated, of which 68 participants (28.2\%) reported de novo headaches since the start of the pandemic. Incidence of pre-existing headaches (odds ratio $[\mathrm{OR}]=1.91$; $95 \%$ confidence interval $[\mathrm{Cl}]$ : 0.99 $0.37 ; p=0.049$ ) was associated with new-onset headaches. Post hoc multivariable logistic regression analysis stated that incidence of pre-existing headaches $(\mathrm{OR}=1.88$; $95 \% \mathrm{Cl}: 0.94-3.78 ; p=0.75)$ and age $(\mathrm{OR}=2.21 ; 95 \% \mathrm{Cl}: 0.47-10.33 ; p=0.36)$ was independently associated with new-onset PPE-induced headaches but was not statistically significant. Chi-squared analysis showed a statistically significant relationship
DOI https://doi.org/ 10.1055/s-0040-1721904 ISSN 1305-7456. (c) 2020. European Journal of Dentistry.

This is an open access article published by Thieme under the terms of the Creative Commons Attribution-NonDerivative-NonCommercial-License, permitting copying and reproduction so long as the original work is given appropriate credit. Contents may not be used for commercial purposes, or adapted, remixed, transformed or built upon. (https://creativecommons.org/licenses/by-nc-nd/4.0/)

Thieme Medical and Scientific Publishers Pvt. Ltd., A-12, 2nd Floor, Sector 2, Noida-201301 UP, India 
between other factors (sleep deprivation, emotional stress, etc.) and department of activity, gender, and occupation $(p<0.05)$.

Conclusion Healthcare workers with previous history of pre-existing headaches were found to be more susceptible to PPE-induced headaches during COVID-19 pandemic. However, age and the department where the healthcare workers performed may also be risk factors.

\section{Introduction}

The world is in the throes of the coronavirus disease 2019 (COVID-19) pandemic for which the viral agent responsible is severe acute respiratory syndrome coronavirus 2 (SARS-CoV-2). The initial cases of COVID-19 were identified in Wuhan, China, in December, 2019 that later spread rapidly to almost all the countries around the globe. ${ }^{1}$ Most of the human infections caused by coronaviruses are mild except for those caused by SARS-CoV and Middle East respiratory syndrome-related coronavirus, which belong to betacoronaviruses, which have been responsible for two major previous outbreaks., ${ }^{2,3}$ The virus spreads mainly through contact, respiratory droplets, and eye exposure; therefore, respiratory and eye protection is required to guard from it. ${ }^{4,5}$ For the currently foreseeable future (i.e., until a safe and effective vaccine or treatment becomes available for this disease), COVID-19 prevention will continue to rely on nonpharmaceutical interventions, including pandemic mitigation in community settings ${ }^{6}$.

In January 2020, COVID-19 was included as group B category of infectious diseases by the National Health Commission of China, which necessitate the same protection measures for healthcare workers as indicated for group A infections. ${ }^{7}$ By January 30, 2020, the World Health Organization declared COVID-19 a Public Health Emergency of International Concern. ${ }^{8}$

During the escalation of COVID-19 spread, healthcare workers manned the frontlines and wearing of personal protective equipment (PPE) was made mandatory for all the healthcare workers coming in contact with the COVID-19 patients. ${ }^{9}$ PPE includes N-95 mask, protective eyewear, gowns covering from head to toe, surgical gloves, and powered air-purifying respirators. ${ }^{10}$ However, in Pakistan, due to shortages of supplies, 3M KN-95 masks with or without surgical facemasks were also reportedly used in many hospitals as replacement for $\mathrm{N}-95$ masks as part of PPE.

Previous literature has reported that wearing of bands around the head in the form of protective eyewear and facemasks has been identified as an etiological factor for headaches. ${ }^{11}$ In patients with pre-existing headaches, this may lead to exacerbation of pain if the stimulus is prolonged. According to literature, the possible mechanism can be compression of occipital and trigeminal nerves. ${ }^{12}$ Additionally, previous researches addressed the ergonomic problems with the use of PPE such as poor fit and discomfort while having it on..$^{13-15}$ The current coronavirus pandemic has provided the authors with the opportunity to study the association between long-term use of PPE and headaches caused by it among healthcare workers. This study hypothesized that PPE-induced headaches can occur de novo by the compression of pericranial tissues by tight bands and straps of N-95/KN-95 masks, respirators, and protective eyewear in conjunction with increased duty hours. This can also cause exacerbation of pre-existing headache disorders. Limited literature is available on this correlation and none in the Pakistani population. The main aim of this study was to determine the likelihood of new-onset PPE-induced headaches and exacerbation of pre-existing headaches with PPE usage. Furthermore, this study attempted to assess the impact of these headaches on work performances of healthcare workers.

\section{Materials and Methods}

A descriptive cross-sectional survey was conducted across Pakistan in June-July, 2020. The study was approved by Ethical Committee, Armed Forces Institute of Dentistry, Rawalpindi (IRB form no.905/Trg-ABP 1K2). A qualitative questionnaire was developed on Google Forms Inc, which was reviewed by three senior neurologists to assess accuracy. Sampling frame included health professionals from various disciplines working in both public/private medical and dental institutions across Pakistan during the COVID-19 pandemic. Informed consent was acquired from all participants.

The questionnaire was shared via different social networks (e.g., WhatsApp, Instagram, and Facebook), reaching an approximate of 260 individuals. The sample size was calculated using the WHO formula and, with a confidence level of $95 \%$, margin of error $5 \%$, prevalence (on the basis of previous literature ${ }^{7}$ ) of $81 \%$, a sample of 236 was finalized. The questionnaire was made unavailable upon reaching 241 responses, with a response rate of 93\%. Inclusion criteria involved healthcare workers performing duties during the COVID-19 pandemic with respiratory protection (in the form of N-95 masks or KN-95 masks) and/or protective eyewear (goggles, face shields or safety glasses). Exclusion criteria were all the healthcare workers who were not currently practicing.

Convenient sampling technique was used for data collection. The questionnaire was divided into five sections. The first section comprised of demographic data including gender, age, ethnicity, occupation, subspecialty, and department of work, while the second section comprised of PPE-usage patterns data, including the type of respiratory and eye protection used as well as the number of hours per day and days per month worn. 
The third section was related to history of pre-existing headaches (if present). The fourth section dealt with any changes in the frequency and intensity of pre-existing headaches since the start of the pandemic, while the fifth section dealt with the history of new-onset headaches s(if experienced) since the start of the pandemic as well as some personal views of the participants.

\section{Statistical Analyses}

Data was entered in and analyzed on SPSS version 23 for Windows (SPSS Inc, 2003, Chicago, Illinois, United States). Descriptive analysis was performed on demographic data. Chi-squared analysis was performed between demographic data and PPE-usage patterns among participants with or without de novo headaches. Univariable and multivariable logistic regression models were used to compare variables with the development of new-onset headaches. To enhance sensitivity, the variables with a univariable association of $<0.2$ were then, analyzed on the multivariable logistic regression model. Chi-squared test was also performed between demographic data and other factors that may be causing new-onset headaches. A $p$-value $<0.05$ was considered significant.

\section{Results}

A total of 241 healthcare workers (mean age of $28.5 \pm 6.2$ ) participated in this study, of which $53.1 \%$ were males $(n=128)$ and $46.9 \%$ females $(n=113)$. On the basis of occupation, $70.5 \%$ were doctors $(n=170)$, followed by dentists $(n=53,22 \%)$ and nurses ( $n=10,4.1 \%)$. Majority were Punjabis ( $n=139,57.7 \%$ ), aged 23 to 30 years $(n=198,82.2 \%$ ), worked in the COVID-19 isolation wards ( $n=66,27.4 \%$ ). Of 241 respondents, $21.1 \%$ $(n=51)$ had pre-existing headache disorders (see - Table $\mathbf{1})$. Of participants with pre-existing headaches, $37.3 \%(n=19)$ reported migraines, $25.5 \%(n=13)$ had tension-type headaches, while $23.5 \%(n=12)$ reported migraines with aura.

The study concluded that protective eyewear was used by participants on an average of 5.3 hours per day, 18.7 days a month with face shield being the most commonly used gear. Protective respiratory wear was donned on average of 8.2 hours per day, 21.9 days a month and both respiratory wear and eyewear combined were used 6.5 hours per day, 18.9 days a month.

Out of 241, 68 participants (28.2\%) reported de novo headaches since the start of the pandemic, with majority describing the headache as bilateral in location ( $n=47,69 \%)$, with pressure/heaviness in quality ( $n=31,45.5 \%)$ and moderate in intensity $(n=45,66 \%)$.

Incidence of pre-existing headaches (odds ratio $[\mathrm{OR}]=1.91$; 95\% confidence interval [CI]: 0.99-0.37; $p=0.049$ ) was associated with new-onset headaches. Age $(\mathrm{OR}=3.13,95 \% \mathrm{CI}$ : $0.69-14.08 ; p=0.118)$ and department of activity $(\mathrm{OR}=1.12$; 95\% CI: $0.73-1.73 ; p=0.433$ ) had an increased chance of causing new-onset headaches but were not statistically significant (see - Table 2).

Post hoc multivariable logistic regression analysis stated that incidence of pre-existing headaches $(\mathrm{OR}=1.88$; $95 \% \mathrm{CI}$ : 0.94-3.78; $p=0.75$ ) and age (OR $=2.21 ; 95 \% \mathrm{CI}: 0.47-10.33$;
Table 1 Demographic characteristics of 241 healthcare workers

\begin{tabular}{|c|c|c|}
\hline \multicolumn{2}{|c|}{ Characteristics } & \multirow{2}{*}{$\begin{array}{l}\text { Healthcare } \\
\text { workers, } n \text { (\%) } \\
128(53.1) \\
\end{array}$} \\
\hline Gender & Male & \\
\hline & Female & $113(46.9)$ \\
\hline \multirow[t]{2}{*}{ Age } & $23-40$ & 224 (92.9) \\
\hline & $>40$ & $17(7.1)$ \\
\hline \multirow[t]{2}{*}{ Ethnicity } & Punjabi & $139(57.7)$ \\
\hline & Non-Punjabi & $102(42.3)$ \\
\hline \multirow[t]{4}{*}{ Occupation } & Doctor & $170(70.5)$ \\
\hline & Dentist & $53(22)$ \\
\hline & Nurse & $10(4.1)$ \\
\hline & $\begin{array}{l}\text { Other } \\
\text { healthcare } \\
\text { workers }\end{array}$ & $8(3.3)$ \\
\hline \multirow[t]{5}{*}{ Department } & $\begin{array}{l}\text { COVID-19 } \\
\text { isolation ward }\end{array}$ & $66(27.4)$ \\
\hline & Dental clinic & $52(21.6)$ \\
\hline & $\begin{array}{l}\text { Emergency } \\
\text { department }\end{array}$ & $38(15.8)$ \\
\hline & Medical clinic & $34(14.1)$ \\
\hline & Others & $51(21.2)$ \\
\hline \multirow{2}{*}{$\begin{array}{l}\text { Duration of use of } \\
\text { respiratory protection }\end{array}$} & $<4 \mathrm{~h}$ & $24(10)$ \\
\hline & $>4 \mathrm{~h}$ & $217(90)$ \\
\hline \multirow{2}{*}{$\begin{array}{l}\text { Duration of use of eye } \\
\text { protection }\end{array}$} & $<4 \mathrm{~h}$ & $108(44.8)$ \\
\hline & $>4 \mathrm{~h}$ & $133(55.2)$ \\
\hline \multirow{2}{*}{$\begin{array}{l}\text { Duration of use of } \\
\text { respiratory and eye } \\
\text { protection }\end{array}$} & $<4 \mathrm{~h}$ & $76(31.5)$ \\
\hline & $>4 h$ & $165(68.5)$ \\
\hline \multicolumn{2}{|c|}{ Incidence of pre-existing headaches } & $51(21.1)$ \\
\hline
\end{tabular}

Abbreviation: COVID-19, coronavirus disease 2019.

$p=0.36)$ was independently associated with new-onset PPE-induced headaches but was not statistically significant (see - Table 3).

Out of the 68 participants with new-onset headaches, 16 (23.5\%) stated that the headache started more than 2 hours after donning PPE, while 19 (27.9\%) participants stated that the headache ended between 1-2 hours after doffing of PPE. Fifty-three respondents (77.9\%) experienced the headaches for 4 or less days per month.

- Fig. 1 shows that 28 (41.2\%) participants believed that it was very likely that the combined use of respiratory and eye protection was the cause of these de novo headaches, while $19(27.9 \%)$ respondents attributed it to other factors. In a multiple response question, participants were asked about other factors which, according to them, may be contributing to their new-onset headaches. Forty-three participants (22.4\%) out of 68 believed that sleep deprivation may be the cause of these headaches, instead of PPE use (see $\boldsymbol{- F i g . ~ 2 ) . ~ A ~ s t a t i s t i c a l l y ~ s i g - ~}$ nificant relationship was established between these factors and department of work ( $p=0.033)$, gender $(p=0.0017)$, and occupation (0.017), when chi-squared analysis was done. 
Table 2 Analysis of factors (demographic variables, primary location of PPE usage, pre-existing primary headache diagnosis, and PPE usage in respondents with and without de novo PPE-associated headaches)

\begin{tabular}{|c|c|c|c|c|}
\hline Demographic variables & $\begin{array}{l}\text { With de novo PPE- } \\
\text { related headaches, } \\
n=68(\%)\end{array}$ & $\begin{array}{l}\text { Without de novo PPE- } \\
\text { related headaches, } \\
n=173(\%)\end{array}$ & OR $(95 \% \mathrm{Cl})$ & $p$-Value ${ }^{\mathrm{a}}$ \\
\hline Gender, male & $28(41.1)$ & $100(57.8)$ & $0.51(0.29-0.90)$ & $0.020^{\mathrm{b}}$ \\
\hline \multicolumn{5}{|l|}{ Age $(y)$} \\
\hline $23-40$ & $66(97)$ & $158(91.3)$ & $3.13(0.69-14.08)$ & 0.118 \\
\hline$>40$ & $2(2.9)$ & $15(8.6)$ & & \\
\hline \multicolumn{5}{|l|}{ Ethnicity } \\
\hline Punjabi & $35(51.4)$ & $104(60.1)$ & $0.70(0.40-1.24)$ & 0.222 \\
\hline Non-Punjabis & $33(48.5)$ & $69(39.9)$ & & \\
\hline \multicolumn{5}{|l|}{ Occupation } \\
\hline Doctor and dentist & $59(86.7)$ & $164(94.7)$ & $0.36(0.13-0.95)$ & $0.033^{\mathrm{b}}$ \\
\hline Others & $9(13.2)$ & $9(5.2)$ & & \\
\hline \multicolumn{5}{|l|}{ Department } \\
\hline COVID-19 isolation ward & $22(32.4)$ & $44(25.4)$ & $1.12(0.73-1.73)$ & 0.433 \\
\hline Emergency & $12(17.6)$ & $27(15.6)$ & & \\
\hline Others & $34(50)$ & $102(58.9)$ & & \\
\hline Incidence of pre-existing headaches & $20(29.4)$ & $31(17.9)$ & $1.91(0.99-0.37)$ & $0.049^{\mathrm{b}}$ \\
\hline \multicolumn{5}{|c|}{ Duration of respiratory protection use per day } \\
\hline$>4 h$ & $62(91.1)$ & $155(89.6)$ & $0.83(0.32-2.20)$ & 0.712 \\
\hline $1-4 \mathrm{~h}$ & $6(8.8)$ & $18(10.4)$ & & \\
\hline \multicolumn{5}{|c|}{ Frequency of respiratory protection use per month } \\
\hline$>15 d$ & $56(82.3)$ & $131(75.7)$ & $0.72(0.35-1.48)$ & 0.369 \\
\hline $3-15 d$ & $12(17.6)$ & $39(22.5)$ & & \\
\hline \multicolumn{5}{|l|}{ Duration of eye protection use per day } \\
\hline$>4 h$ & $42(61.7)$ & $91(52.6)$ & $0.69(0.39-1.22)$ & 0.198 \\
\hline $1-4 h$ & $26(38.2)$ & $82(47.4)$ & & \\
\hline \multicolumn{5}{|c|}{ Frequency of eye protection use per month } \\
\hline$>15$ & $47(69.1)$ & $110(63.6)$ & $0.91(0.50-1.67)$ & 0.762 \\
\hline $3-15 d$ & $21(30.9)$ & $54(31.2)$ & & \\
\hline \multicolumn{5}{|c|}{ Frequency of use of combined eye and respiratory protection per month } \\
\hline$>15$ & $48(70.6)$ & $10(63.6)$ & $0.83(0.45-1.54)$ & 0.560 \\
\hline $3-15 d$ & $20(29.4)$ & $55(31.8)$ & & \\
\hline \multicolumn{5}{|c|}{ Frequency of use of combined eye and respiratory protection per day } \\
\hline$>4$ & $48(70.6)$ & $117(67.6)$ & $0.87(0.47-1.60)$ & 0.656 \\
\hline $1-4 \mathrm{~h}$ & $20(29.4)$ & $56(32.4)$ & & \\
\hline
\end{tabular}

Abbreviations: Cl, confidence interval; COVID-19, coronavirus disease 2019; OR, odds ratio.

astatistically significant results.

${ }^{\mathrm{b}} \mathrm{Chi}$-squared analyses. 
Table 3 Multivariable logistic regression analysis of independent factors and PPE-usage patterns associated with the development of de novo PPE-associated headaches $(n=68)$

\begin{tabular}{|l|l|l|}
\hline $\begin{array}{l}\text { Demographic } \\
\text { variables }\end{array}$ & $\begin{array}{l}\text { Odds ratio }(95 \% \\
\text { confidence interval) }\end{array}$ & $p$-Value \\
\hline Gender, male & $0.65(0.35-1.21)$ & 0.176 \\
\hline $\begin{array}{l}\text { Age }(y) \\
23-40 \\
>40\end{array}$ & $2.21(0.47-10.33)$ & 0.316 \\
\hline $\begin{array}{l}\text { Occupation: } \\
\text { Doctor and dentist } \\
\text { Others }\end{array}$ & $0.45(0.16-1.26)$ & 0.129 \\
\hline $\begin{array}{l}\text { Incidence of pre-existing } \\
\text { headaches }\end{array}$ & $1.88(0.94-3.78)$ & 0.075 \\
\hline $\begin{array}{l}\text { Duration of eye protec- } \\
\text { tion use per day } \\
>4 \\
1-4 \text { h }\end{array}$ & $0.69(0.37-1.27)$ & 0.236 \\
\hline
\end{tabular}

aMultiple logistic regression.

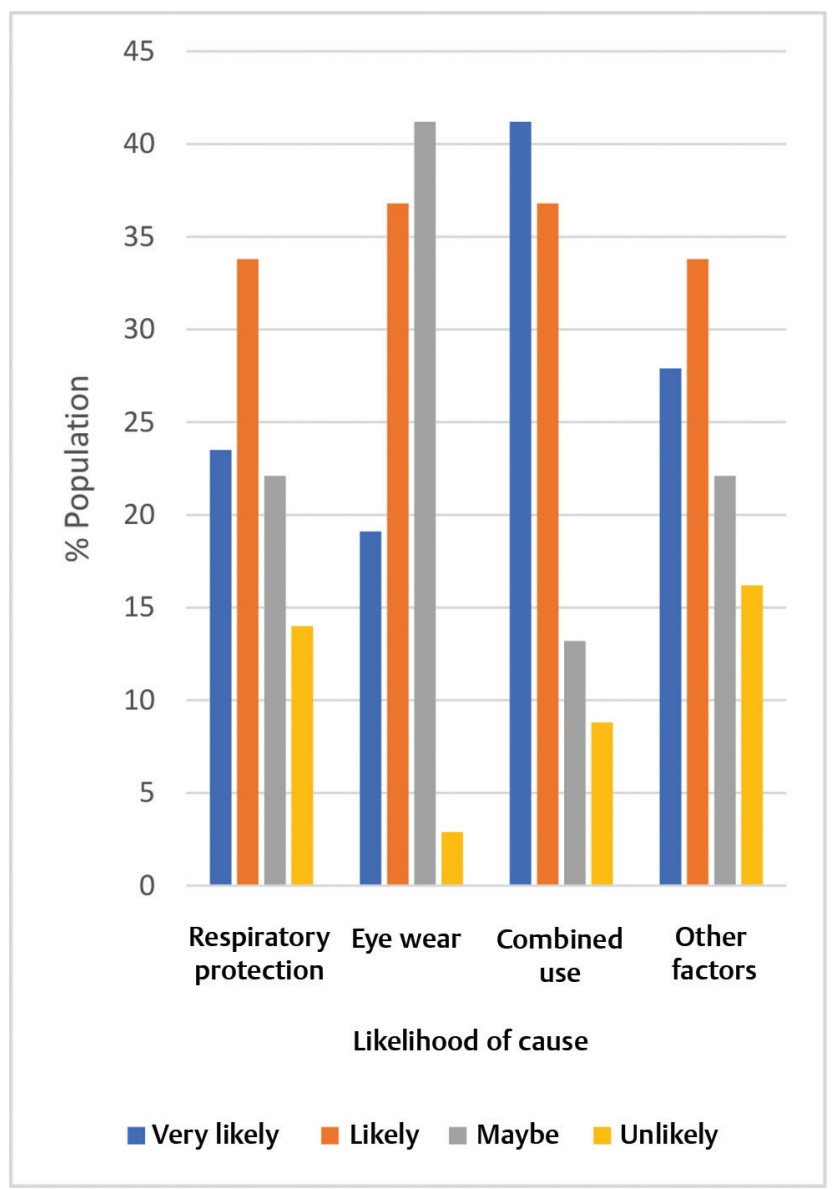

Fig. 1 Causes attributed to the increase in frequency of headaches.

\section{Discussion}

This study attempts to establish a relationship between headaches and PPE usage in healthcare workers of Pakistan. Nearly $30 \%$ of the respondents reported the incidence of

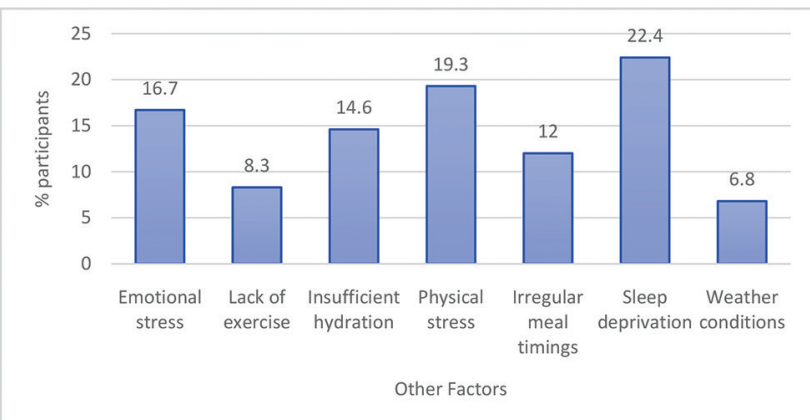

Fig. 2 Other factors attributing to new onset headaches.

new-onset headache with the use of respiratory protection such as KN95/N95 masks and eye protection. This study was based on the previous studies conducted by Lim et al and Ong et al. ${ }^{11,16}$ Both studies found that pre-existing headaches and excessive usage of respiratory and eye protection increase the risk of headaches. ${ }^{11,16}$ However, in this study, only individuals with a previous history of pre-existing headaches were found to be more susceptible to de novo PPE-induced headaches.

Majority of the participants made use of abortive medication ( $n=58,86.7 \%$ ) with 17 (25\%) taking medications more than 10 days per month. Forty individuals (65.6\%) took paracetamol as an abortive medication, while nonsteroidal anti-inflammatory drugs were the second most common choice ( $n=19,31.1 \%$ ). These results corroborated with those of Lim et al. ${ }^{16}$ However, 41 healthcare workers (60.3\%) did not require any sick leaves due to these headaches.

PPE usage has been the main mode of protection for healthcare workers such as doctors and dentists as both are repeatedly exposed to aerosol-generating procedures. ${ }^{17-20}$ The use of surgical masks alone cannot provide enough protection for such procedures. Although surgical facemasks induce less discomfort, breathing difficulty, and stress, wearing of N95 masks becomes necessary when dealing with COVID-19 patients. ${ }^{21}$ In Pakistan, due to severe shortage of facilities, N95/KN95 masks were used with or without concurrent application of surgical masks. In his research article, Roberge proposed that the life of an N95 respirator mask could be prolonged by concurrently wearing a surgical mask, with the latter being changed repeatedly. However, this combination of respiratory protection may negatively impact the wearer physiologically and psychologically, and may also impair communication. ${ }^{22}$ In our study, 116 participants (46.1\%) wore surgical masks in combination with N95 masks.

Donning of PPE is a tedious and uncomfortable job, especially if worn for a long period of time. ${ }^{23}$ Buildup of moist warm air is linked with the use of respiratory mask and protective eyewear, resulting in thermal discomfort. ${ }^{24}$ Additionally, the use of face shields and eye goggles reflects and refracts the light making observation stressful thus leading to eye fatigue. ${ }^{25,26}$ Several etiological factors may be linked to pathogenesis of de novo PPE-associated headaches. The main factors include stress, hypercapnia, hypoxemia, and mechanical factors. ${ }^{7,22}$ The International Classification of Headache Disorders has already linked hypoxemia and hypercarbia 
with headaches..$^{27}$ Rebmann et al observed hypoxemia with the use of N95 masks for more than 4 hours, along with rapid respiratory rate and chest discomfort, ${ }^{28}$ while Or et al associated the tight elastic head straps of N95 respirators with headache, facial pain, and/or ear lobe discomfort. ${ }^{29}$ In this study, majority of the participants associated sleep deprivation as the main cause of these new-onset headaches, while no previous studies correlated other etiological factors as the causative agent other than PPE.

Another type of headache, which is caused by exacerbation of head movements or sustained awkward head positions, called cervicogenic headache, is normally linked to an underlying cervical pathology. ${ }^{27,30}$ Use of close fitting N95 mask, protective eyewear, goggles, and helmets can cause headaches due to sustained pressure from the strap on the neck or over the back of the head, thus compressing the superficial nerves underneath, mainly the occipital nerve, which has been identified as one of the causes of unremitting head and neck pain. ${ }^{31}$ This has been supported in this study as majority of the healthcare workers with de novo headaches also complained of neck discomfort ( $n=22,33.8 \%$ ). Furthermore, out of 51 individuals who had pre-existing headaches, 20 also experienced new-onset headaches since the start of the pandemic.

One of the major contributors of headache is stress, ${ }^{32}$ which leads to tension-type headache. Since the start of the pandemic, most of the healthcare workers have reported an increase in the intensity of their pre-existing headaches, lack of sleep, emotional, and physical stress. This can also be associated with the increase in frequency of headaches since March 2020.33,34 These types of headaches were also observed during the SARS outbreak in 2003. ${ }^{35}$ Another study conducted among the medical intensive care unit nurses wearing respirators showed headache as one of the etiological factors for decreased compliance of N95 facemask use. ${ }^{28,36}$ Other reasons may be increased duty hours, inadequate food and water intake, separation from families, and excessive exertion. ${ }^{37}$ In this study, 211 healthcare workers $(87.9 \%)$ were working greater than 10 hours per week, of which 63 (26.2\%) were working in COVID-19 isolation wards. Lim et $\mathrm{al}^{16}$ reported facemask-associated headaches in $37.3 \%$ of the respondents, while Ong et a ${ }^{11}$ stated that $81 \%$ of the participants had PPE-associated headaches with N95 facemask with or without the protective eyewear use. However, the authors believe that the decreased incidence of headaches $(28.2 \%)$ in this study, may be due to the majority of healthcare workers having become acclimatised to the poor working conditions in the country.

It is acknowledged that there are several limitations to this study. Due to shortage of N95 supplies among hospitals, KN95 mask use was also included in this study as part of PPE. Recall bias was limited as the questionnaire was filled by participants during the peak of COVID-19 pandemic in Pakistan.

\section{Conclusion}

Healthcare workers with previous history of pre-existing headaches were found to be more susceptible to PPE-induced headaches during COVID-19 pandemic. However, age and department of activity may also be risk factors. Proper guidelines need to be set up to prevent prolonged use of PPE to alleviate the problems being faced by healthcare workers during this pandemic.

\section{Conflict of Interest}

None declared.

\section{References}

1 Huang C, Wang Y, Li X, et al. Clinical features of patients infected with 2019 novel coronavirus in Wuhan, China. Lancet 2020;395(10223):497-506

2 Ksiazek TG, Erdman D, Goldsmith CS, et al; SARS Working Group. A novel coronavirus associated with severe acute respiratory syndrome. N Engl J Med 2003;348(20):1953-1966

3 de Groot RJ, Baker SC, Baric RS, et al. Middle East respiratory syndrome coronavirus (MERS-CoV): announcement of the Coronavirus Study Group. J Virol 2013;87(14):7790-7792

4 Peng X, Xu X, Li Y, Cheng L, Zhou X, Ren B. Transmission routes of 2019-nCoV and controls in dental practice. Int J Oral Sci 2020;12(1):9. doi:10.1038/s41368-020-0075-9

5 Azim AA, Shabbir J, Khurshid Z, Zafar MS, Ghabbani HM, Dummer PMH. Clinical endodontic management during the COVID-19 pandemic: a literature review and clinical recommendations. Int Endod J 2020;53(11):1461-1471

6 Qualls N, Levitt A, Kanade N, et al; CDC Community Mitigation Guidelines Work Group. Community mitigation guidelines to prevent pandemic influenza - United States, 2017. MMWR Recomm Rep 2017;66(1):1-34

7 Meng L, Hua F, Bian Z. Coronavirus disease 2019 (covid-19): emerging and future challenges for dental and oral medicine. J Dent Res 2020;99(5):481-487

8 World Health Organisation. Timeline of WHO's response to COVID-19. Available at: https://www.who.int/news-room/detail/ 29-06-2020-covidtimeline. Accessed August 24, 2020.

9 Verbeek JH, Rajamaki B, Ijaz S, et al. Personal protective equipment for preventing highly infectious diseases due to exposure to contaminated body fluids in healthcare staff. Cochrane Database Syst Rev 2020;4(4):CD011621

10 Khoo K-L, Leng P-H, Ibrahim IB, Lim TK. The changing face of healthcare worker perceptions on powered air-purifying respirators during the SARS outbreak. Respirology 2005; 10(1):107-110

11 Ong JJ, Bharatendu C, Goh Y, et al. Headaches associated with personal protective equipment - a cross-sectional study among frontline healthcare workers during covid-19. Headache 2020;60(5):864-877

12 Krymchantowski AV. Headaches due to external compression. Curr Pain Headache Rep 2010;14(4):321-324

13 Akbar-Khanzadeh F. Factors contributing to discomfort or dissatisfaction as a result of wearing personal protective equipment. J Hum Ergol (Tokyo) 1998;27(1-2):70-75

14 de Almeida RAC dos S, Veiga MM, de Castro Moura Duarte FJ, Meirelles LA, Veiga LBE. Thermal comfort and personal protective equipment (PPE) Work 2012;41(Suppl 1) :4979-4982

15 Grugle NL, Kleiner BM. Effects of chemical protective equipment on team process performance in small unit rescue operations. Appl Ergon 2007;38(5):591-600

16 Lim ECH, Seet RCS, Lee K-H, Wilder-Smith EPV, Chuah BYS, Ong BKC. Headaches and the N95 face-mask amongst healthcare providers. Acta Neurol Scand 2006;113(3):199-202

17 Hamid H, Khurshid Z, Adanir N, Zafar MS, Zohaib S. COVID-19 pandemic and role of human saliva as a testing biofluid in point-of-care technology. Eur J Dent 2020;14(suppl S1): S123-S129 doi:10.1055/s-0040-1713020 
18 Alharbi A, Alharbi S, Alqaidi S. Guidelines for dental care provision during the COVID-19 pandemic. Saudi Dent J 2020;32(4):181-186

19 Guo H,Zhou Y, Liu X, Tan J. The impact of the COVID-19 epidemic on the utilization of emergency dental services [published online ahead of print, 2020 Mar 16]. J Dent Sci 2020;10.1016/j. jds.2020.02.002 doi:10.1016/j.jds.2020.02.002

20 Khurshid Z, Asiri FYI, Al Wadaani H. Human saliva: non-invasive fluid for detecting novel coronavirus (2019nCoV). Int J Environ Res Public Health 2020;17(7):2225 doi:10.3390/ijerph17072225

21 Li Y, Tokura H, Guo YP, et al. Effects of wearing N95 and surgical facemasks on heart rate, thermal stress and subjective sensations. Int Arch Occup Environ Health 2005;78(6):501-509

22 Roberge RJ. Effect of surgical masks worn concurrently over N95 filtering facepiece respirators: extended service life versus increased user burden. J Public Health Manag Pract 2008; 14(2):E19-E26

23 Wong JEL, Leo YS, Tan CC. COVID-19 in Singapore-current experience: critical global issues that require attention and action. JAMA 2020;323(13):1243-1244

24 Locatelli SM, LaVela SL, Gosch M. Health care workers' reported discomfort while wearing filtering face-piece respirators. Workplace Health Saf 2014;62(9):362-368

25 Loibner M, Hagauer S, Schwantzer G, Berghold A, Zatloukal K. Limiting factors for wearing personal protective equipment (PPE) in a health care environment evaluated in a randomised study. PLoS One 2019;14(1):e0210775 Published 2019 Jan 22 doi:10.1371/journal.pone.0210775

26 Yánez Benítez C, Güemes A, Aranda J, et al; International Cooperation Group on PPE and Emergency Surgery. Impact of personal protective equipment on surgical performance during the COVID-19 pandemic. World J Surg 2020;44(9):2842-2847

27 ICHD-II Classification: Parts 1-3: Primary, Secondary and Other. Cephalalgia. 2004 May 1;24(1_suppl):23-136.

28 Rebmann T, Carrico R, Wang J. Physiologic and other effects and compliance with long-term respirator use among medical intensive care unit nurses. Am J Infect Control 2013;41(12):1218-1223

29 Or PP, Chung JW, Wong TK. A study of environmental factors affecting nurses' comfort and protection in wearing N95 respirators during bedside procedures. J Clin Nurs 2018;27(7-8):e1477-e1484

30 Fishbain DA, Antonaci F, Bono G. Cervicogenic headache. Cephalalgia 2002;22(10):829-830, discussion 829-830

31 Blake P, Burstein R. Emerging evidence of occipital nerve compression in unremitting head and neck pain. J Headache Pain 2019;20(1):76

32 Martin PR. Stress and primary headache: Review of the research and clinical management. Curr Pain Headache Rep 2016;20(7):45 doi:10.1007/s11916-016-0576-6

33 Pellegrino ABW, Davis-Martin RE, Houle TT, Turner DP, Smitherman TA. Perceived triggers of primary headache disorders: a meta-analysis. Cephalalgia 2018;38(6):1188-1198

34 Chew NWS, Lee GKH, Tan BYQ et al. A multinational, multicentre study on the psychological outcomes and associated physical symptoms amongst healthcare workers during COVID-19 outbreak. Brain Behav Immun 2020;88:559-565

35 McAlonan GM, Lee AM, Cheung V, et al. Immediate and sustained psychological impact of an emerging infectious disease outbreak on health care workers. Can J Psychiatry 2007;52(4):241-247

36 Baig AS, Knapp C, Eagan AE, Radonovich LJ Jr. Health care workers' views about respirator use and features that should be included in the next generation of respirators. Am J Infect Control 2010;38(1):18-25

37 Moazzami B, Razavi-Khorasani N, Dooghaie Moghadam A, Farokhi E, Rezaei N. COVID-19 and telemedicine: Immediate action required for maintaining healthcare providers well-being. J Clin Virol 2020;126:104345 doi:10.1016/j. jcv.2020.104345 